\title{
ANALYSIS OF FRP CONFINED COLUMNS UNDER ECCENTRIC LOADING
}

\author{
Bernát Csuka* , László P. Kollár* \\ * Department of Mechanics, Materials and Structures \\ Budapest University of Technology and Economics \\ Müegyetem rkp. 1-3, 1521 Budapest, Hungary \\ e-mail: csukab.sil@silver.szt.pme.hu, web page: http://www.szt.bme.hu
}

Key words: FRP confined, Eccentrically loaded, Circular, Rectangular, Concrete, Column.

Summary. A new model for eccentrically loaded FRP confined concrete or reinforced concrete columns is presented. With the aid of this model we wish to predict the experimental data and to explain the behavior of confined columns under eccentric loading.

\section{INTRODUCTION}

Load bearing capacity of axially loaded concrete and reinforced concrete columns can be improved by using lateral confinement. In the last two decades the use of FRP confinement has significantly increased due to its high corrosion resistance, high ultimate stress and because it is easy to use. FRP confinement is most frequently applied for circular and rectangular cross-sections (with rounded edges).

\section{PROBLEM STATEMENT}

The existing models for eccentrically loaded columns [1] are based on expressions for the more simple case of concentric loading. They fail to properly predict the behavior of the confined columns under eccentric loads. We present a new model with the aid to predict the experimental data and to explain the behavior of confined columns.
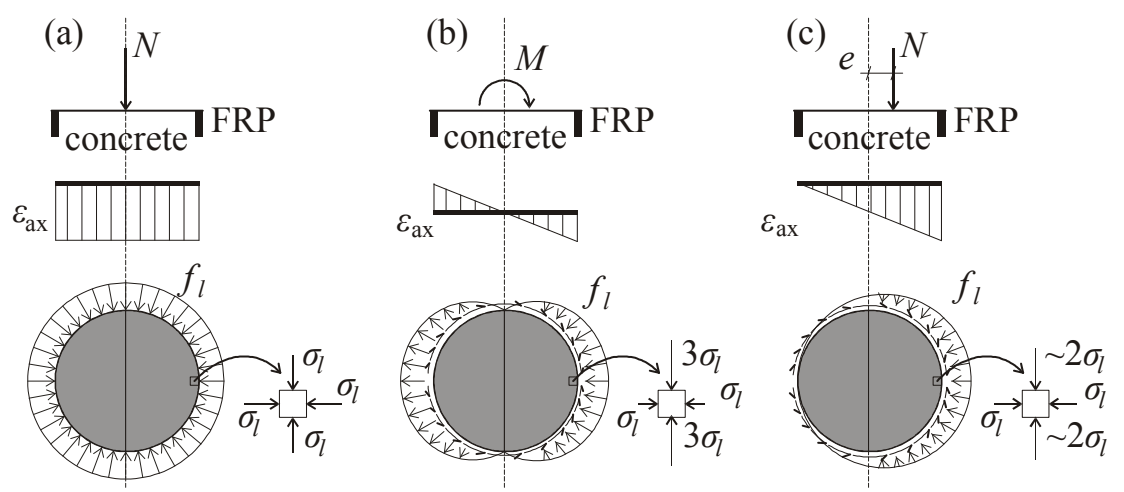

Figure 1: Strains and stresses of confined columns subjected to concentric load (a), bending (b) and eccentric load (c) 


\section{METHOD OF SOLUTION}

The effect of confinement is different for concentric- and for eccentric loading as indicated in Figure 1. A finite element model was developed for the calculation of the cross-section [2]. The finite element mesh is two-dimensional, however the strains and stresses are threedimensional: it is assumed that the axial strain varies linearly through the cross-section and the nonlinearly varying axial stress is calculated based on the concrete material law proposed by Papanikolaou and Kappos [3].

\section{CONCLUSIONS}

We compared our results with the experimental data found in the literature and a good correlation was found (Figure 2).
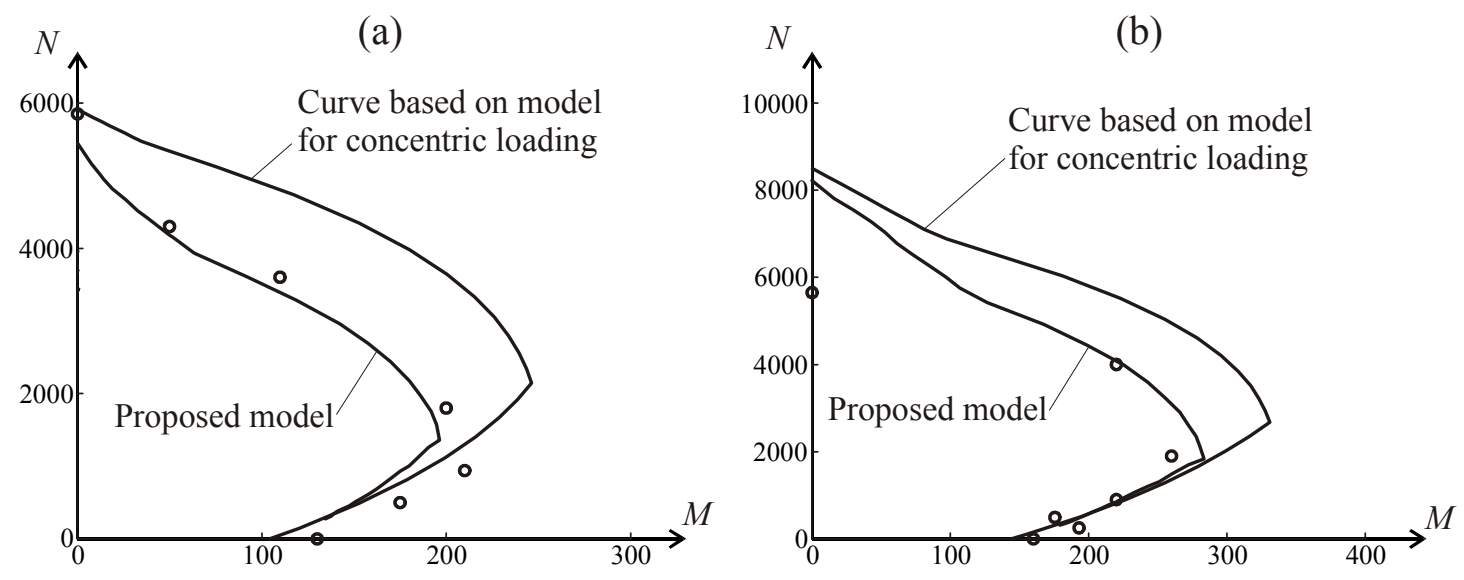

Figure 1: Comparison of experimental results and models

The following observations can be made:

- the maximum axial stress of eccentrically loaded columns roughly agrees with the axial stress of concentrically loaded columns,

- the average axial stress decreases rapidly as the eccentricity increases, much faster than it is predicted by previous models.

Based on the results new stress-strain curves for confined concrete were recommended for a simplified model.

\section{REFERENCES}

[1] L. Bisby and M. Ranger, "Axial-flexural interaction in circular FRP-confined reinforced concrete columns", Construction and Building Materials, 24, 1672-1681 (2010).

[2] B. Csuka and L. P. Kollár, "FRP confined circular concrete columns subjected to concentric loading", J. of Reinforced Plastics and Composites, 29(23): 3504-3520 (2010).

[3] V. K. Papanikolaou and A. J. Kappos, "Confinement-sensitive plasticity constitutive model for concrete in triaxial compression", Int. J. of Solids and Structures., 44, 70217048 (2007). 